\title{
Optimization of an Agrobacterium-mediated Transient Assay for Gene Expression Studies in Anthurium andraeanum
}

\author{
Fazeeda N. Hosein, Adrian M. Lennon, and Pathmanathan Umaharan ${ }^{\mathbf{1}}$ \\ Department of Life Sciences, Faculty of Science and Agriculture, The University of the West Indies, \\ St. Augustine Campus, College Road, The Republic of Trinidad and Tobago
}

\begin{abstract}
Additional INDEX words. Agrobacterium tumefaciens, transient gene expression, inoculation media, leaves
Abstract. Gene function studies in anthurium (Anthurium andraeanum) have been hindered by the low efficiency of stable transformation, the long regeneration time required as well as the genotype-dependent nature of Agrobacterium (Agrobacterium tumemaciens)-mediated transformation protocols. Agrobacterium-mediated transient expression assays can serve as an attractive alternative for investigating gene function once such assays are optimized. The effects of host factors (genotype, explant type, and developmental maturity of explants), Agrobacterium factors (strain, growth phase, and its concentration), media conditions (infiltration medium used, acetosyringone concentration, type of surfactant, and its concentration), and other experimental factors (infiltration time, cocultivation time, and vacuum infiltration) were investigated on the efficiency of Agrobacterium transient transformation, with replications, using transient expression of $\beta$-glucuronidase as an indicator. Although the efficiency of transient transformation was initially found to be highly host genotype-dependent, the genotypic differences in transient transformation efficiency diminished as the protocol was optimized. Agrobacterium strain GV3101 grown to an optical density at $600 \mathrm{nM}\left(\mathrm{OD}_{600}\right)$ of 1.5 and resuspended to a final $\mathrm{OD}_{600}$ of 0.8 in infiltration medium [0.5\% glucose, $10 \mathrm{~mm} 2$-( $N$-morpholino) ethanesulfonic acid] supplemented with $100 \mu \mathrm{M}$ acetosyringone and $0.05 \%$ of a non-ionic surfactant (S240), for an infiltration period of 16 hours and a cocultivation timeframe of 2 days yielded transient transformation efficiencies as high as $100 \%$.
\end{abstract}

Anthurium andraeanum, a member of the family Araceae (monocotyledon), is highly prized as an ornamental plant with its beautiful flowers and exotic foliage (Dufour and Guérin, 2003). As is the case with other monocots, anthurium is not naturally susceptible to Agrobacterium-mediated transformation but can be transformed under the right conditions (Chen et al., 1997; Fitch et al., 2011; Zhao et al., 2010). Stable transformation of anthurium has been achieved using a variety of constructs, Agrobacterium strains, and explants types (etiolated internodes, root section, calli) (Chen and Kuehnle, 1996; Chen et al., 1997; Fitch et al., 2011; Kuehnle and Chen, 1994; Kuehnle et al., 2001, 2004; Zhao et al., 2010) with reported transformation efficiencies reaching up to $2 \%$ (Fitch et al., 2011). The generation of transgenic plants of anthurium, using the aforementioned methods, is labor-intensive and takes years before results can be properly assessed (Fitch et al., 2011; Zhao et al., 2010).

Transient genetic transformation (Fischer and Emans, 2000; van der Hoorn et al., 2000; Yasmin and Debener, 2010) provides a rapid means of assessing gene constructs (Kapila et al., 1997; Manavella and Chan, 2009) compared with stable genetic transformation, allowing results to be obtained in days. Although both Agrobacterium-mediated transformation and microparticle bombardment have been widely used in transient assays, the former is less intrusive, more efficient in delivering large gene constructs, and does not require expensive and specialized equipment (Christou, 1997; Fischer and Emans, 2000). Furthermore, particle bombardment in anthurium (Collette, 2002; Hayden and

Received for publication 26 Mar. 2012. Accepted for publication 1 June 2012. We gratefully acknowledge the management and staff of Kairi Blooms Ltd. for providing the plant material for this research. We also thank Evonik Goldschmidt Chemical (Hopewell, VA) for donating Break Thru ${ }^{\mathrm{TM}}$ (S240).

${ }^{1}$ Corresponding author. E-mail: pathmanathan.umaharan@sta.uwi.edu.
Christopher, 2004) has been shown not to be amenable for transient assays as a result of extensive and rapid browning of wounded tissue (Collette, 2002).

Transient Agrobacterium-mediated gene expression assays have been successfully used to analyze gene function ( $\mathrm{Li}$ et al., 2009; Manavella and Chan, 2009), gene silencing (Bhaskar et al., 2009), and gene-for-gene interactions between host resistance and pathogen avirulence genes (Baulcombe 1999; Frederick et al., 1998; Kapila et al., 1997; Scofield et al., 1996; Tsuda et al., 2011). It has also been used to characterize production of recombinant antibodies in tobacco (Nicotiana tabacum) and lettuce (Lactuca sativa) (Negrouk et al., 2005; Vaquero et al., 1999). Although experimental procedures are relatively simple and work well with many plant species such as tobacco, potato (Solanum tuberosum), tomato (Solanum lycopersicum), lettuce, pea (Pisum sativum), grapevine (Vitis vinifera), wheat (Triticum aestivum), and Arabidopsis thaliana (He et al., 2010; Mestre et al., 2000; Santos-Rosa et al., 2008; Tsuda et al., 2011; van der Hoorn et al., 2000; Wroblewski et al., 2005), such procedures have not been developed for anthurium.

Transient transformation assays require an efficient and reliable system that works well over many different genotypes. One of the difficulties with the use of Agrobacterium-mediated transformation has been the genotype-dependent nature of the transformation systems (Chen and Kuehnle, 1996; Chen et al., 1997; Fitch et al., 2011). In this study we demonstrate using leaf explants in which the protocol can be optimized to efficiently transform even the most difficult-to-transform genotypes.

\section{Materials and Methods}

Cultivars AND EXPLANTs. Eight cultivars of $A$. andraeanum (Local Pink, Pierrot, Lydia, Sonata, KAIRI2010, Honduras, 
Mirjam, and Tropical) were used in the study. Leaf, spathe, and spadix explants were collected from anthurium plants grown at a commercial anthurium farm in Carapo village, Arima, Trinidad (Kairi Blooms Ltd.). The cultivars were grown at a spacing of $45 \times 30 \mathrm{~cm}$ in shade houses ( $75 \%$ shade) on beds made of pulverized coconut husk. The leaf explants were collected at three developmental stages: Stage 1, young, unopened leaves; Stage 2, fully expanded young leaves (floppy); and Stage 3, fully expanded, mature and firm leaves. The collected material was transported under ice to the laboratory. Spathe and spadix tissues were collected at Stage 6, in which the spathe is fully expanded but the flowers have not dehisced (Collette et al., 2004). A sterile 10 -mm-diameter cork borer was used to obtain discs $80 \mathrm{~mm}^{2}$ area of both leaf and spathe explants, carefully avoiding the central vascular tissue. The spadix tissue was diced into 5-mm-thick cylindrical pieces and used in the experiments.

Agrobacterium STRaIns and PlaSmid. The three Agrobacterium strains used, EHA 101, LBA 4404, and GV3101, contain disarmed Ti plasmids pTiBo542, pTiAch5, and pTiC58, respectively. These strains were transformed with pCAMBIA1305.2 (Brisbane, Australia) containing both a CaMV 35S promoter and the $\beta$-glucuronidase (GUS) gene. The GUS gene contained within the plasmid included an intron. The Agrobacterium strains were grown to different growth phases corresponding to $\mathrm{OD}_{600}$ of $0.1,0.5,0.8,1.0$, and 1.5 and diluted to $\mathrm{OD}_{600}$ of 0.8 to investigate the effect of Agrobacterium growth phase and concentration on the efficiency of transient transformation.

AGRobacterium inoculation. Unless otherwise stated all experiments used the "initial transformation protocol" (ITP) as described subsequently. Bacterial cells, grown to an $\mathrm{OD}_{600}$ of 1.5 , were collected and suspended to a final $\mathrm{OD}_{600}$ of 0.5 in an infiltration medium consisting of $5 \%$ sucrose supplemented with $0.05 \%$ of the surfactant S240 (Break Thru $^{\mathrm{TM}}$; Evonik Goldschmidt Chemical, Hopewell, VA) and $100 \mu \mathrm{M}$ acetosyringone (Sigma-Aldrich, St. Louis, MO). The explants were immersed in the infiltration solution for $4 \mathrm{~h}$ immediately after cutting and were subsequently washed with sterile water with vigorous shaking to remove excess Agrobacterium. They were then transferred in $25 \mathrm{~mL}$ of $1 / 4$ Murashige and Skoog (MS) salts, in low light $\left(0.3 \mu \mathrm{mol} \cdot \mathrm{m}^{-2} \cdot \mathrm{s}^{-1}\right)$, with gentle agitation $(100 \mathrm{rpm})$ in an Erlenmeyer flask $(250 \mathrm{~mL})$ at room temperature $\left(22 \pm 2^{\circ} \mathrm{C}\right)$ for $2 \mathrm{~d}$.

$\beta$-GluCURonidase histochemical assays. For $\beta$-glucuronidase (GUS) assays, the discs were immersed in a GUS staining solution $\left(0.1 \mathrm{M} \mathrm{NaH}_{2} \mathrm{PO}_{4}, 0.1 \mathrm{M} \mathrm{Na}_{2} \mathrm{HPO}_{4}, 10 \mathrm{~mm}\right.$ EDTA pH $8,0.5 \mathrm{M}$ potassium ferrocyanide, $0.5 \mathrm{M}$ potassium ferricyanide, 1 mм 5-bromo-4-chloro-3-indolyl- $\beta$-D-glucuronic acid [X-Gluc (Research Products International, Mount Prospect, IL)] and incubated at $37^{\circ} \mathrm{C}$ in the dark, overnight. Leaf discs were then transferred to $75 \%$ ethanol to remove the green coloration imparted by chlorophyll. The results were recorded as percentage of the explants that showed a blue coloration.

EXPERIMENTATION. First, explants from eight cultivars were treated with the ITP to identify those that were most recalcitrant to transient transformation and those that were most easily transformed. Two selected cultivars, representing one easily transformed and the other recalcitrant to transient transformation, were then used to investigate explants source, infiltration medium, Agrobacterium strain, Agrobacterium growth phase, and concentration and length of cocultivation. Then holding those variables constant, type of surfactant, surfactant concentration, acetosyringone concentration, and length of vacuum infiltration were tested on transient transformation efficiency assayed by GUS histochemical assay and reported as percentage of the explants transformed. Each experiment was carried out in a randomized complete block design with three replications with each replication consisting of 10 explants.

Cultivar effects. Leaf discs (Stage 2 leaves) from eight cultivars (Local Pink, Pierrot, Lydia, Sonata, KAIRI2010, Honduras, Mirjam, and Tropical) were subjected to the ITP as described before using the Agrobacterium strain EHA101 and subjected to GUS histochemical assays.

THE EFFECT OF EXPLANTS AND DEVELOPMENTAL STAGE. Three explants (leaf, spathe, and spadix), with the leaf explants at three developmental stages as described before, of cultivars Local Pink and KAIRI2010 (representing the easily transformed and recalcitrant to transformation, respectively) were used to investigate the effect of explant and developmental stage on transient transformation efficiency with two Agrobacterium strains, EHA101 and GV3101, and using the ITP before assaying for GUS activity.

EFFECT OF GROWTH PHASE OF Agrobacterium AND Cocultivation time. The growth curves for the three Agrobacterium strains were determined by inoculating single colonies of each strain into Luria Broth medium, incubating at $28{ }^{\circ} \mathrm{C}$ with agitation $(200 \mathrm{rpm})$, and by serially sampling aliquots over a 36 -h period and recording the optical density at $600 \mathrm{nM}$. To investigate the effect of Agrobacterium strain, growth phase, and cocultivation time on transient transformation efficiency, three Agrobacterium strains (described before) were grown to varying optical densities $\left(\mathrm{OD}_{600}\right.$ of $\left.0.1,0.5,1.0,1.5\right)$ and suspended to a final $\mathrm{OD}_{600}$ of 0.5 and subjected to the ITP but varying cocultivation time as follows: $0,1,2,3$, or $4 \mathrm{~d}$ using anthurium ('Local Pink' and 'KAIRI2010') with Stage 2 leaf discs. The treatments, three Agrobacterium strains, four growth phases, and four cocultivation times, were factorially combined and arranged in a randomized complete block design with three replications with replications conducted over time. Each treatment combination consisted of 10 explants.

Effect of Agrobacterium concentration. The effect of Agrobacterium concentration on transient transformation efficiency was investigated using two strains of Agrobacterium (EHA101 and GV3101). Each strain was grown to an $\mathrm{OD}_{600}$ of 1.5 and suspended to a final $\mathrm{OD}_{600}$ of $0.01,0.05,0.10,0.50$, $0.80,1.00$, and 1.50 in infiltration medium (ITP). The inocula were used to inoculate leaf discs of 'Local Pink' (Stage 2) as described before and cocultivated for $1,2,3,4$, or $5 \mathrm{~d}$. The Agrobacterium strains (two), concentrations (seven), and cocultivation times (five) were combined in a factorial structure and replicated three times. Each treatment combination consisted of 10 explants. The experiment was analyzed as a randomized complete block design.

EFFeCt of INFILTRATION MEdium. The effect of infiltration medium on transient transformation efficiency of 'Local Pink' and 'KAIRI 2010' (Stage 2 leaves) was investigated using two strains of Agrobacterium (EHA 101 and GV3101) each grown to an $\mathrm{OD}_{600}$ of 1.5 and suspended to a final $\mathrm{OD}_{600}$ of 0.5 in the five different infiltration media (IF1-IF5; shown subsequently), supplemented with $0.05 \%$ S240 and $100 \mu \mathrm{M}$ acetosyringone and cocultivated for $2 \mathrm{~d}$ as before, and assayed for GUS activity:

IF $1-1 \%$ glucose; IF2 - $5 \%$ sucrose; 
IF3 - 0.5\% glucose, $10 \mathrm{~mm}$ 2-(N-morpholino) ethanesulfonic acid (MES), $10 \mathrm{~mm}$ magnesium chloride;

IF4 - $1 / 4 \mathrm{MS}, 1 \%$ sucrose; and

IF5 - 1/10 MS, 20 mm 3-(N-morpholino) propanesulfonic acid, $2 \%$ sucrose, $1 \%$ glucose.

The cultivars, Agrobacterium strains, and infiltration media were arranged in a factorial structure with 10 explants per treatment combination with the experiment replicated three times.

EFfect of Surfactant. The effect of type of surfactant on transient transformation efficiency was determined as follows. The bacterial cells (EHA101 and GV3101) were collected at an $\mathrm{OD}_{600}$ of 1.5 and suspended to a final $\mathrm{OD}_{600}$ of 0.8 in the infiltration medium (IF4 for 'Local Pink' and IF2 for 'KAIRI2010') supplemented with $100 \mu \mathrm{M}$ acetosyringone and either of $0.01 \%$ of Tween- 20 (Research Organics, Cleveland, $\mathrm{OH})$, Triton-X 100 (Labchem, Pittsburgh, PA), or S240. After Agrobacterium inoculation, the explants ('Local Pink' and 'KAIRI2010' Stage 2 leaves) were cocultivated for $2 \mathrm{~d}$ before assaying for GUS activity. The two cultivars, two Agrobacterium strains, and the three surfactants were combined in a factorial structure and replicated three times over time with 10 explants per treatment combination.

EfFect of SuRfactant Concentration. To determine the concentration that yielded the best results, varying concentrations of the S240 surfactant were used $(0.005 \%, 0.01 \%, 0.02 \%$, $0.05 \%$, and $0.1 \%$ ). The bacterial cells were collected at $\mathrm{OD}_{600}$ of 1.5 and suspended to a final $\mathrm{OD}_{600}$ of 0.8 in the infiltration medium (IF4 for 'Local Pink' and IF2 for 'KAIRI2010') supplemented with varying concentrations of S240 and $100 \mu \mathrm{M}$ acetosyringone. After Agrobacterium inoculation, the explants (Stage 2 leaves) were cocultivated for $2 \mathrm{~d}$ before assaying for GUS activity. The two cultivars, two Agrobacterium strains, and the five concentrations of S240 were combined in a factorial structure and replicated three times over time with 10 explants per treatment combination.

EFFECT OF ACETOSYRINGONE CONCENTRATION. The bacterial cells grown to $\mathrm{OD}_{600}$ of 1.5 were collected and suspended to a final $\mathrm{OD}_{600}$ of 0.8 in the infiltration medium (either IF2 or IF4) supplemented with $0.005 \%$ of S240 and varying concentrations of acetosyringone $(10,20,50,100,200$, and $500 \mu \mathrm{M})$. After Agrobacterium inoculation, the explants ('Local Pink' and 'KAIRI2010'; Stage 2 leaves) were cocultivated for $2 \mathrm{~d}$ before assaying for GUS activity. The two cultivars, two Agrobacterium strains, and the six concentrations of acetosyringone were combined in a factorial structure and replicated three times over time with 10 explants per treatment combination.

EFFect Of VACUUm infiLtration. To determine the effect of vacuum infiltration as well as the duration of it on transient transformation efficiency, varying infiltration times were tested $(0,1,5,10,20$, or $30 \mathrm{~min})$ with two cultivars and two Agrobacterium strains. The bacterial cells were collected and resuspended to a final $\mathrm{OD}_{600}$ of 0.8 in the infiltration medium supplemented with $0.005 \%$ of S240 and $100 \mu \mathrm{M}$ acetosyringone. The leaf discs were immersed in the infiltration solution immediately after cutting and were subjected to vacuum infiltration for the durations indicated previously. The discs were subsequently washed with sterile water with vigorous shaking to remove the excess Agrobacterium. They were then incubated in 1/4 MS medium, in low light, with gentle agitation $(100 \mathrm{rpm})$ at room temperature $\left(22 \pm 2{ }^{\circ} \mathrm{C}\right)$. Two days after transformation, 10 discs ('Local Pink' and 'KAIRI2010'; Stage 2 leaves) were stained for GUS activity and transient transformation efficiency calculated as outlined previously.

Statistical Analyses. Analyses of variance were carried out using the statistical software NCSS (NCSS, Kaysville, UT) to detect significance of main effects and interactions. The percentage data were subjected to arcsine transformation before analysis. Differences between the treatments were compared using Fisher's least significant difference test.

\section{Results}

As previously stated, eight cultivars were tested using an ITP. One easily transformable and one recalcitrant cultivar were then used to investigate explants source, infiltration medium, Agrobacterium strain, Agrobacterium growth phase, and concentration and length of cocultivation. Holding those variables constant, type of surfactant, surfactant concentration, acetosyringone concentration, and length of vacuum infiltration were then tested.

Cultivar effects. There were significant $(P<0.001)$ differences in the transient transformation efficiency among the eight cultivars tested (Fig. 1) with efficiency varying from $0 \%$ ('Tropical') to $83 \% \pm 1.05 \%$ ('Local Pink'). Two cultivars, one easily transformable ('Local Pink') and another with low transient transformation efficiency ('KAIRI 2010'), were used in subsequent experiments.

Tissue TYPE. There were significant differences among the various developmental stages of the leaf $(P<0.001)$ with Stage 2 leaf tissue giving a significantly higher transient transformation efficiency than Stage 1 or Stage 3 in both cultivars and over the two Agrobacterium strains (Fig. 2). On average the transient transformation efficiencies for Stage 2 leaves were $67 \% \pm 2.6 \%$ for 'Local Pink' and 57\% $\pm 2.6 \%$ for 'KAIRI2010'. Although the spadix explants showed consistently poor transient transformation efficiencies across both cultivars, the spathe explants of the two cultivars exhibited differential response to Agrobacterium inoculation accounting for the significant cultivar $\times$ tissue type interaction. Although the spathe explants showed high transient transformation efficiency in 'KAIRI2010', they showed no evidence of transient transformation over the various replicates in 'Local Pink'.

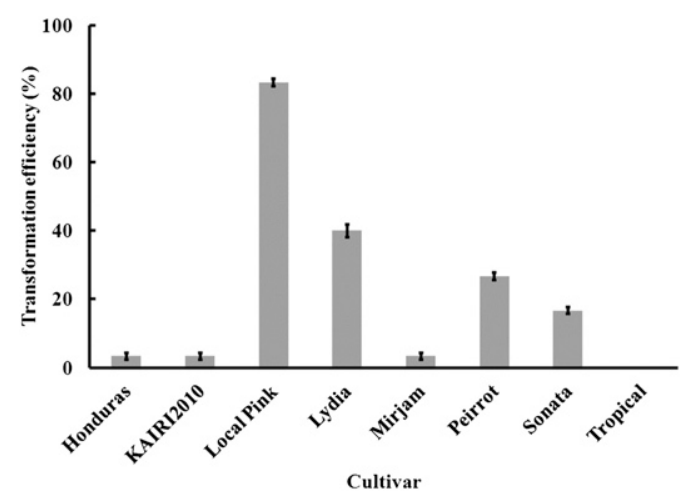

Fig. 1. Transformation efficiencies (mean $\pm \mathrm{SE}$ ) obtained with leaf explants of eight cultivars of anthurium. Means and SE were determined from three independent experiments $(n=30)$. 
A
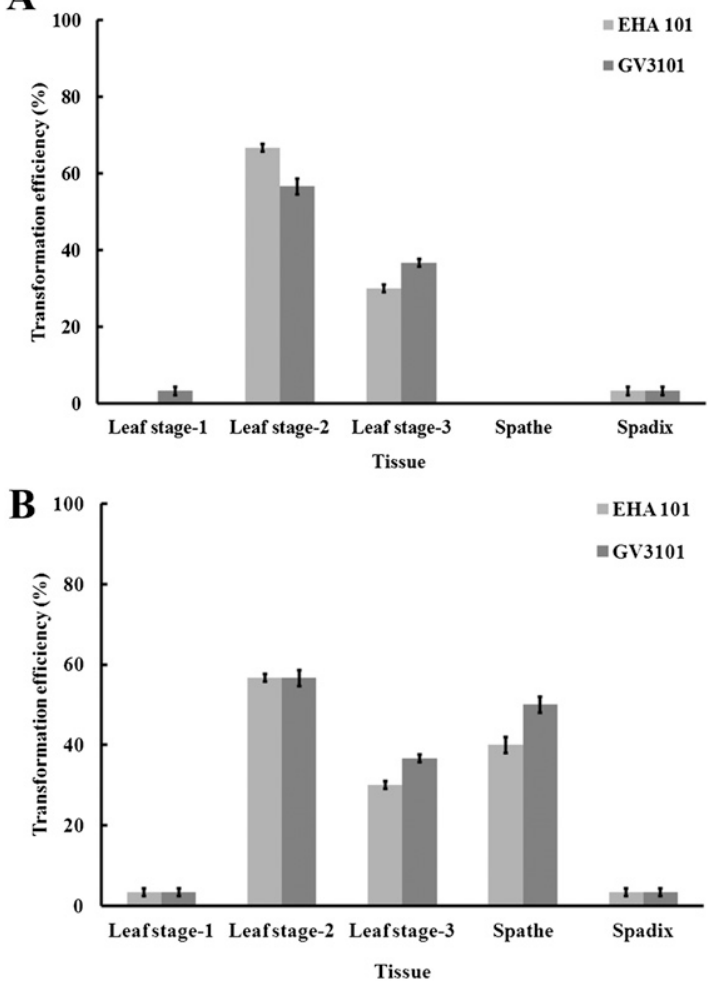

Fig. 2. The effect of tissue type and leaf developmental stage on transformation efficiency (mean $\pm \mathrm{SE}$ ) in anthurium cultivars Local Pink (A) and KAIRI2010 (B). Means and SE were determined from three independent experiments $(\mathrm{n}=$ 30); Stage 1, young, unopened leaves; Stage 2, fully expanded young leaves (floppy); Stage 3, fully expanded, mature and firm leaves. Spathe and spadix tissues were collected at Stage 6, in which the spathe is fully expanded but the flowers have not dehisced. EHA101 (C58 chromosomal background with disarmed pTiBo542) and GV3101 (C58 chromosomal background with disarmed pTiC58) are Agrobacterium strains.

INFILTRATION MEDIA. The main effects of cultivar and infiltration media as well as the cultivar $\times$ media interaction effect were significant $(P<0.001)$ on transient transformation efficiency. The effect of Agrobacterium strain was not significant $(P>0.05)$. Among the five inoculation media tested, IF4 gave the highest transient transformation efficiency in 'Local Pink' $(83 \% \pm 4.5 \%)$ followed by IF2 $(57 \% \pm 1.05 \%)$, whereas IF2 gave the highest transient transformation efficiency $(70 \% \pm$ $4.5 \%$ ) in 'KAIRI2010' (Fig. 3). The other media on average gave $\approx 14 \%$ transient transformation efficiency in both cultivars. Thus, for subsequent experiments, IF2 was selected for 'KAIRI 2010' and IF4 for 'Local Pink'.

Agrobacterium STRain, GROWTH PHASE, aNd COCULTIVATION TIME. Although the main effects of cultivar $(P<0.001)$, Agrobacterium strain $(P<0.001)$, growth phase $(P<0.001)$, and cocultivation time $(P<0.001)$ were significant, the effects of growth phase $(\mathrm{F}=230)$ and cocultivation time $(\mathrm{F}=260)$ were by far the greatest. Hence, in general regardless of cultivar or Agrobacterium strain, the maximum transient transformation efficiencies were obtained at the Agrobacterium growth phase corresponding to an $\mathrm{OD}_{600}$ of 1.5 (midlog phase) and with a cocultivation time of $2 \mathrm{~d}$ (Table 1). The only notable exceptions were with Agrobacterium strain LBA 4404, in which the transient transformation efficiencies were not significantly different between $\mathrm{OD}_{600}$ of 0.5 and 1.5 and between 2 and $3 \mathrm{~d}$ of
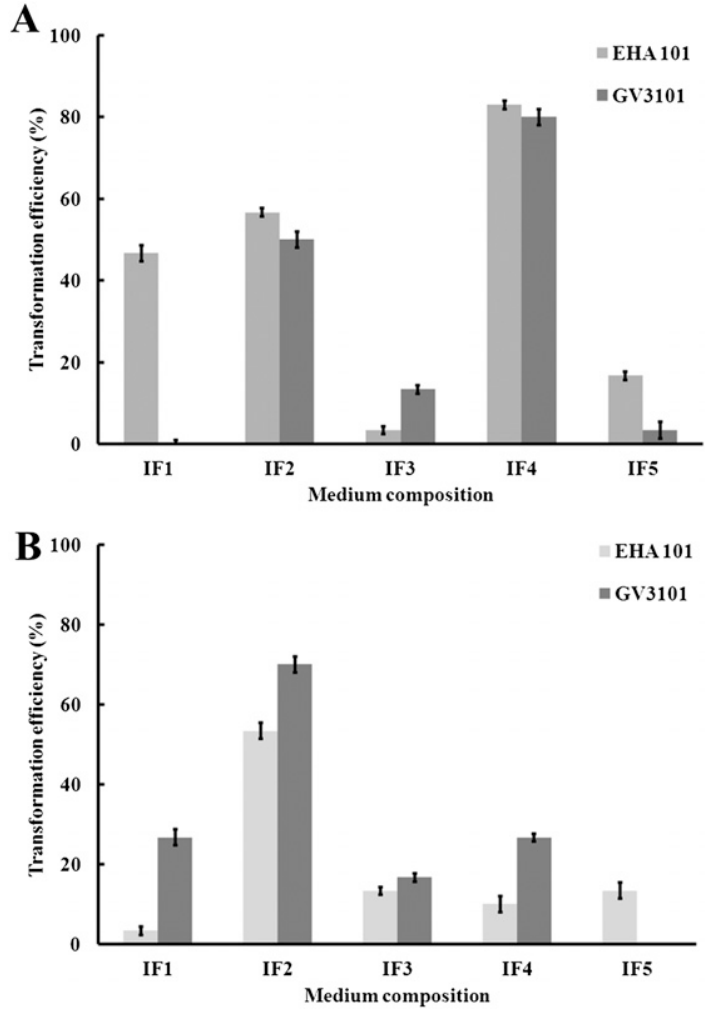

Fig. 3. The effect of infiltration media (IF) on transformation efficiencies (mean \pm SE) of anthurium cultivars Local Pink (A) and KAIRI2010 (B); IFI $=1 \%$ glucose; IF2 $=5 \%$ sucrose; IF3 $=0.5 \%$ glucose $+10 \mathrm{~mm} 10 \mathrm{~mm} 2-(\mathrm{N}-$ morpholino) ethanesulfonic acid $+10 \mathrm{mM} \mathrm{MgCl} 2 ; \mathrm{IF} 4=1 / 4$ Murashige and Skoog salts (MS) $+1 \%$ glucose; IF5 = 1/10 MS + 20 mм 3-(N-morpholino) propanesulfonic acid $+2 \%$ sucrose $+1 \%$ glucose. Means and SE were determined from three independent experiments $(\mathrm{n}=30)$. EHA101 (C58 chromosomal background with disarmed pTiBo542) and GV3101 (C58 chromosomal background with disarmed pTiC58) are Agrobacterium strains.

cocultivation (at $\mathrm{OD}_{600}$ of 1.0), accounting for the significant second-order interaction. Notwithstanding, at the optimum growth phase and cocultivation time, the transient transformation efficiencies were significantly higher for EHA101 and GV3101 compared with LBA 4404 (Table 1). It can be concluded that for both EHA101 and GV3101, maximum transient transformation with respect to both cultivars can be obtained when the Agrobacterium strains are grown to an $\mathrm{OD}_{600}$ of 1.5 and explants subjected to a 2-d cocultivation. These conditions were adhered to in subsequent experiments.

Agrobacterium Concentration. Various concentrations of Agrobacterium were compared at the optimum growth phase as determined in the previous experiment using the Agrobacterium strains EHA101 and GV3101. The main effects of cultivar $(P<$ $0.001)$, Agrobacterium strain $(P<0.05)$, and Agrobacterium concentration $(P<0.001)$ as well as the cultivar $\times$ Agrobacterium strain interaction effect $(P<0.05)$ were significant. Regardless of the Agrobacterium strain used, the optimum concentration was at a dilution equivalent to $\mathrm{OD}_{600}$ of 0.8 , which resulted in a mean transient transformation efficiency of $85 \%$ (Fig. 4). Although there were no significant differences between the two Agrobacterium strains used in cultivar KAIRI2010, strain EHA101 proved to be significantly $(P<0.05)$ better than GV3101 with respect to 'Local Pink', accounting for the interaction. 
Table 1. The effects of Agrobacterium strain, growth phase, and cocultivation time on transformation efficiencies of anthurium cultivars Local Pink and KAIRI2010. ${ }^{\mathrm{z}}$

\begin{tabular}{|c|c|c|c|c|c|c|c|c|c|}
\hline \multirow[b]{4}{*}{ Agrobacterium strain } & \multirow[b]{4}{*}{$\mathrm{OD}_{600}{ }^{\mathrm{y}}$} & \multicolumn{8}{|c|}{ Transformation efficiency [mean \pm SE $(\%)]$} \\
\hline & & \multicolumn{5}{|c|}{ 'Local Pink' } & \multicolumn{3}{|c|}{ 'KAIRI2010' } \\
\hline & & \multicolumn{5}{|c|}{ Cocultivation time $(\mathrm{d})$} & \multicolumn{3}{|c|}{ Cocultivation time $(\mathrm{d})$} \\
\hline & & 0 & 1 & 2 & 3 & 0 & 1 & 2 & 3 \\
\hline \multirow{3}{*}{ EHA101 } & 0.1 & $0 \pm 0$ & $9 \pm 1.1$ & $23 \pm 1.1$ & $4 \pm 1.1$ & $0 \pm 0$ & $7 \pm 1.1$ & $20 \pm 1.1$ & $3 \pm 1.1$ \\
\hline & 0.5 & $0 \pm 0$ & $19 \pm 1.1$ & $31 \pm 1.1$ & $22 \pm 2.6$ & $0 \pm 0$ & $10 \pm 2.6$ & $30 \pm 1.1$ & $8 \pm 2.6$ \\
\hline & 1.0 & $0 \pm 0$ & $41 \pm 1.1$ & $56 \pm 2.6$ & $20 \pm 2.6$ & $0 \pm 0$ & $30 \pm 2.6$ & $55 \pm 2.6$ & $17 \pm 2.6$ \\
\hline \multirow[t]{5}{*}{ LBA4404 } & 0.0 & $0 \pm 0$ & $0 \pm 0$ & $0 \pm 0$ & $0 \pm 0$ & $0 \pm 0$ & $0 \pm 0$ & $0 \pm 0$ & $0 \pm 0$ \\
\hline & 0.1 & $0 \pm 0$ & $11 \pm 1.1$ & $28 \pm 1.1$ & $2 \pm 1.1$ & $0 \pm 0$ & $8 \pm 1.1$ & $18 \pm 1.1$ & $4 \pm 1.1$ \\
\hline & 0.5 & $0 \pm 0$ & $10 \pm 1.1$ & $63 \pm 1.1$ & $7 \pm 1.1$ & $0 \pm 0$ & $10 \pm 1.1$ & $30 \pm 1.1$ & $6 \pm 1.1$ \\
\hline & 1.0 & $0 \pm 0$ & $12 \pm 2.6$ & $52 \pm 3$ & $53 \pm 2.6$ & $0 \pm 0$ & $10 \pm 1.1$ & $42 \pm 2.6$ & $18 \pm 2.6$ \\
\hline & 1.5 & $0 \pm 0$ & $20 \pm 1.1$ & $58 \pm 2.6$ & $7 \pm 1.1$ & $0 \pm 0$ & $15 \pm 1.1$ & $48 \pm 2.6$ & $22 \pm 1.1$ \\
\hline \multirow{2}{*}{ GV3101 } & 1.0 & $0 \pm 0$ & $15 \pm 1.1$ & $40 \pm 2.6$ & $24 \pm 1.1$ & $0 \pm 0$ & $15 \pm 1.1$ & $30 \pm 2.6$ & $25 \pm 1.1$ \\
\hline & 1.5 & $0 \pm 0$ & $47 \pm 1.1$ & $65 \pm 1.1$ & $67 \pm 2.6$ & $0 \pm 0$ & $40 \pm 1.1$ & $50 \pm 1.1$ & $56 \pm 2.6$ \\
\hline
\end{tabular}

${ }^{\mathrm{z}}$ Means and SES were determined from three independent experiments, where $n=30$.

${ }^{\mathrm{y}}$ Growth phase represented as optical density at $600 \mathrm{nM}$.

Surfactant TYPe AND CONCENTRation. The effect of Agrobacterium strain $(P<0.05)$ and type of surfactant $(P<0.001)$ significantly influenced transient transformation efficiency. Neither the effect of cultivar nor the interactions were significant $(P>0.05)$. Among the three surfactants tested, only S240 gave a higher $(64 \% \pm 1.1 \%)$ transient transformation efficiency when compared with the no surfactant control $(12 \% \pm 2.5 \%)$. The other two surfactants had a deleterious effect on transient transformation indicated by a significantly lower transient transformation percentage compared with the control (Fig. 5). Again, Agrobacterium strain EHA101 resulted in a higher transient transformation percentage $(75 \% \pm 2.5 \%)$ than GV3101 $(50 \% \pm$ $2.5 \%$ ). From these results, S240 was chosen for use in subsequent experiments.

The main effects of Agrobacterium strain $(P<0.01)$ and concentration of the surfactant S240 $(P<0.001)$ as well as the cultivar $\times$ surfactant concentration interaction were significant on transient transformation percentage, whereas the effect of cultivar and other interactions were not significant $(P>0.05)$ (Fig. 6). Although in both cultivars the highest transient transformation efficiency was obtained at the concentration of S240 of $0.005 \%$ ('KAIRI2010'-60\%; 'Local Pink'-76\%), the resulting decline in transient transformation efficiency at concentrations higher than $0.005 \%$ was more pronounced in 'KAIRI2010' compared with 'Local Pink' (Fig. 6). Necrotic damage to the explants was noted at the high concentrations of S240. Again on average the transient transformation efficiency with EHA 101 was superior to GV3101.

Acetosyringone Concentration. Although the main effects of Agrobacterium strain $(P<0.05)$ and acetosyringone concentration $[\mathrm{AC}(P<0.001)]$ as well as the interaction effects [cultivar $\times \mathrm{AC}(P<0.01)$ and Agrobacterium strain $\times \mathrm{AC}(P<$ $0.001)]$ were significant, $\mathrm{AC}$ had the largest effect $(\mathrm{F}=200)$. Hence, regardless of cultivar or Agrobacterium strain, the transient transformation efficiency increased up to the optimum
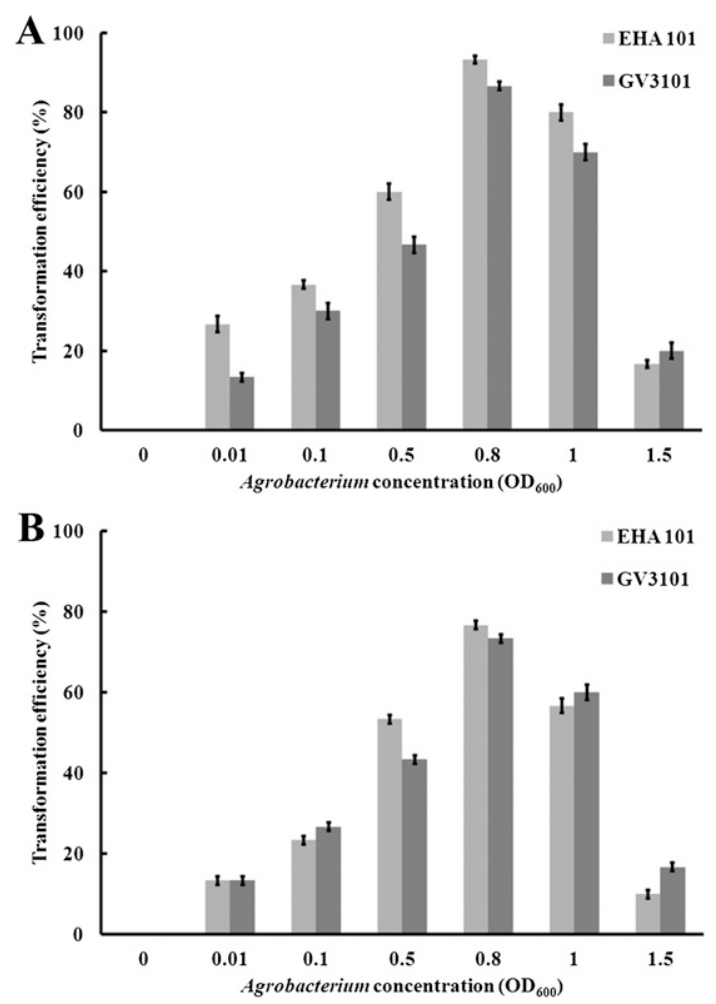

Fig. 4. The effects of Agrobacterium strain [EHA101 (C58 chromosomal background with disarmed pTiBo542), GV3101 (C58 chromosomal background with disarmed pTiC58)] and concentration on transformation efficiencies (mean $\pm \mathrm{SE}$ ) of anthurium cultivars Local Pink (A) and KAIRI2010 (B). Means and SE were determined from three independent experiments $(\mathrm{n}=30) ; \mathrm{OD}_{600}=$ optical density at $600 \mathrm{nM}$. 


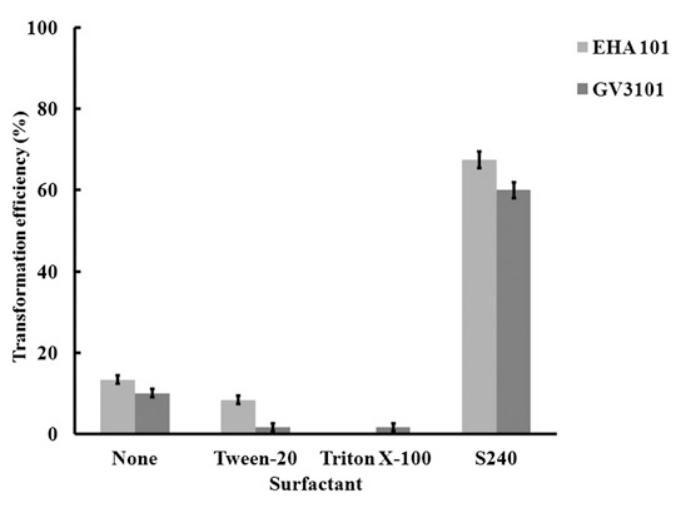

Fig. 5. The effect of Agrobacterium strain [EHA101 (C58 chromosomal background with disarmed pTiBo542), GV3101 (C58 chromosomal background with disarmed pTiC58)], and surfactant [Tween-20 (Research Organics, Cleveland, OH), Triton-X 100 (Labchem, Pittsburgh, PA), S240 (Break Thru ${ }^{\mathrm{TM}}$; Evonik Goldschmidt Chemical, Hopewell, VA)] in infiltration media on transformation efficiencies (mean $\pm \mathrm{SE}$ ) of anthurium. Means and SE were determined from three independent experiments $(n=30)$.

AC of $100 \mu \mathrm{M}$ (average $81 \% \pm 1.9 \%$ ) but declined at higher concentrations (Table 2). Although at the optimal AC, the transient transformation efficiency was significantly higher in 'Local Pink' $(88 \% \pm 2.6 \%)$ than 'KAIRI2010' $(73 \% \pm 2.6 \%)$, at suboptimal concentrations, the transient transformation efficiency in 'KAIRI2010' was significantly better than 'Local Pink', accounting for the cultivar $\times$ AC interaction. Similarly, although up to the optimum AC, EHA101 was either significantly better than or equivalent to GV3101, at above-optimal concentrations of acetosyringone GV3101 gave a higher transient transformation efficiency than EHA101 accounting for the Agrobacterium $\times \mathrm{AC}$ interaction.

INFILTRATION TIME. The main effects of Agrobacterium strain, cultivar, and the infiltration time as well as the interaction effects of cultivar $\times$ Agrobacterium strain and Agrobacterium strain $\times$ infiltration time and cultivar $\times$ Agrobacterium strain $\times$ infiltration time were significant $(P<0.001)$. The effect of cultivar $\times$ infiltration time interaction was however not significant $(P>0.05)$ on transient transformation efficiency. The effect of infiltration time on transient transformation efficiency was the greatest $(\mathrm{F}=171)$ with transient transformation efficiency increasing up to a 16-h infiltration time and decreasing thereafter regardless of cultivar or Agrobacterium strain used (Fig. 7). At the optimum infiltration time, GV3101 elicited a significantly higher transient transformation efficiency of $100 \%$ compared with EHA101 (80\%) in 'Local Pink', but there were no significant differences between EHA101 and GV3101 (average 96\%) in 'KAIRI2010', resulting in a significant $(P<0.001)$ secondorder interaction. On average (over infiltration times), EHA 101 gave a better transient transformation efficiency than GV3101 in 'KAIRI2010' but was not significantly different from GV3101 in 'Local Pink', accounting for the significant Agrobacterium strain $\times$ cultivar interaction. The results also showed that on average EHA101 performed better than GV3101 at lower infiltration times (up to $12 \mathrm{~h}$ ), but GV3101 was equal or better at longer infiltration times, resulting in the significant Agrobacterium strain $\times$ infiltration time interaction. In future experiments, a 16-h infiltration time was used.

VaCUUm infiLtration time. Agrobacterium strain, cultivar, vacuum infiltration time as well as the first- and second-order interaction effects were significant $(P<0.001)$ on transient
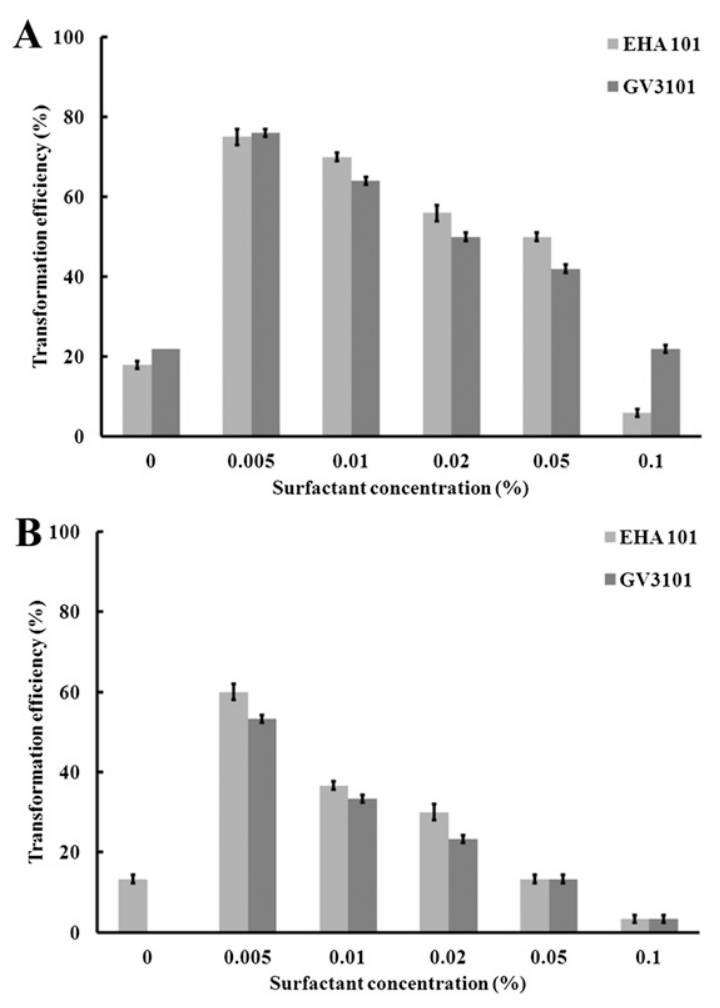

Fig. 6. The effect of Agrobacterium strain [EHA101 (C58 chromosomal background with disarmed pTiBo542), GV3101 (C58 chromosomal background with disarmed pTiC58)], and concentration of the surfactant S240 (Break Thru ${ }^{\mathrm{TM}}$; Evonik Goldschmidt Chemical, Hopewell, VA) on transformation efficiencies (mean $\pm \mathrm{SE}$ ) of anthurium cultivars Local Pink (A) and KAIRI2010 (B). Means and SE were determined from three independent experiments $(\mathrm{n}=30)$.

Table 2. The effect of acetosyringone concentration on transformation efficiencies of two anthurium cultivars, Local Pink and KAIRI2010, transformed with two strains of Agrobacterium, EHA101 and GV3101. ${ }^{z}$

\begin{tabular}{|c|c|c|c|c|}
\hline \multirow{3}{*}{$\begin{array}{l}\text { Acetosyringone } \\
\text { concn }(\mu \mathrm{M})\end{array}$} & \multicolumn{4}{|c|}{ Transformation efficiency [mean \pm SE (\%)] } \\
\hline & \multicolumn{2}{|c|}{ 'Local Pink' } & \multicolumn{2}{|c|}{ 'KAIRI2010' } \\
\hline & EHA10 & $\mathrm{jV} 3101$ & EHA10 & $\mathrm{jV} 3101$ \\
\hline 0 & $0 \pm 0$ & $0 \pm 0$ & $0 \pm 0$ & $0 \pm 0$ \\
\hline 10 & $3 \pm 1.1$ & $3 \pm 1.1$ & $23 \pm 1.1$ & $3 \pm 1.1$ \\
\hline 20 & $17 \pm 1.1$ & $27 \pm 1.1$ & $33 \pm 1.1$ & $20 \pm 1.8$ \\
\hline 50 & $40 \pm 1.8$ & $53 \pm 2.6$ & $60 \pm 1.8$ & $37 \pm 1.1$ \\
\hline 100 & $93 \pm 2.1$ & $83 \pm 1.1$ & $90 \pm 1.8$ & $57 \pm 1.1$ \\
\hline 200 & $3 \pm 1.1$ & $27 \pm 1.1$ & $7 \pm 1.1$ & $23 \pm 1.1$ \\
\hline 500 & $0 \pm 0$ & $0 \pm 0$ & $3 \pm 1.1$ & $0 \pm 0$ \\
\hline
\end{tabular}

${ }^{\mathrm{z}}$ Means and SES were determined from three independent experiments, where $\mathrm{n}=30$.

transformation efficiency. In 'Local Pink', vacuum infiltration resulted in a significant reduction in transient transformation efficiency with no vacuum infiltration having the highest transient transformation efficiency. In the no vacuum infiltration treatment, there were significant differences among the Agrobacterium strains with EHA $101(83 \% \pm 3.5 \%)$ giving a much higher transient transformation efficiency than GV3101 $(19 \% \pm 3.5 \%)$. The trend was very different in 'KAIRI2010', in which GV3101 gave high transient transformation percentage at lower vacuum infiltration times, declining as vacuum infiltration 

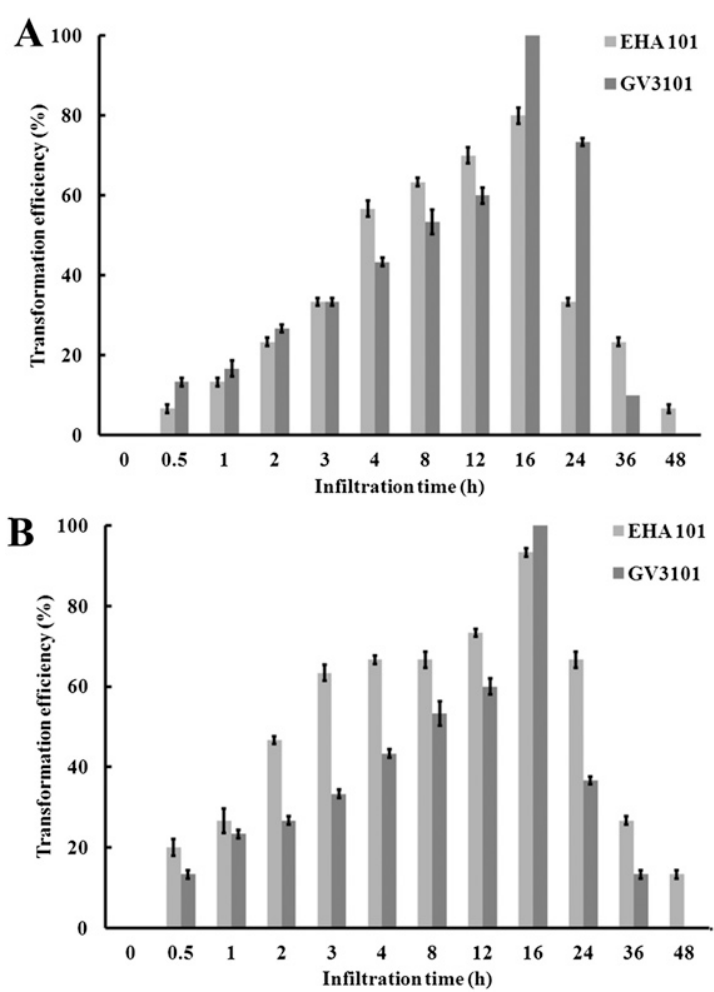

Fig. 7. The effect of Agrobacterium strain [EHA101 (C58 chromosomal background with disarmed pTiBo542), GV3101 (C58 chromosomal background with disarmed pTiC58)], and infiltration time on transformation efficiencies (mean $\pm \mathrm{SE}$ ) of anthurium cultivars Local Pink (A) and KAIRI2010 (B). Means and SE were determined from three independent experiments $(n=30)$.

time exceeded $1 \mathrm{~min}$. In contrast, the transient transformation efficiency obtained with EHA101 steadily increased with increasing vacuum infiltration time reaching a maximum at 20 min after which it declined (Fig. 8). 'KAIRI2010' leaf discs, which were transformed using the vacuum infiltration method, appeared to have a large surface area exhibiting GUS staining when compared with those transformed using no vacuum (data not shown) suggesting that 'KAIRI2010' benefits from vacuum infiltration, particularly when EHA101 is used.

\section{Discussion}

Transient assays provide a useful tool for studying gene function in plants. The use of Agrobacterium-mediated transformation is a fast and highly efficient method, which does not require expensive equipment. Several methods have been published over the years for various plant species in an attempt to improve transformation efficiency (Wroblewski et al., 2005; Zottini et al., 2008).

The results of this study show that the success of Agrobacterium inoculation is dependent on the genotype of the plant, explant type, and developmental stage among others. It has been previously reported that the genetic background of the plant material has a significant impact on the transformation efficiency of lettuce, A. thaliana, grapevine, lentils (Lens culinaris), and rose (Rosa $\times$ hybrida) (Hassan et al., 2007; Santos-Rosa et al., 2008; Wroblewski et al., 2005; Yasmin and Debener, 2010; Zottini et al., 2008). Here, we report transient transformation
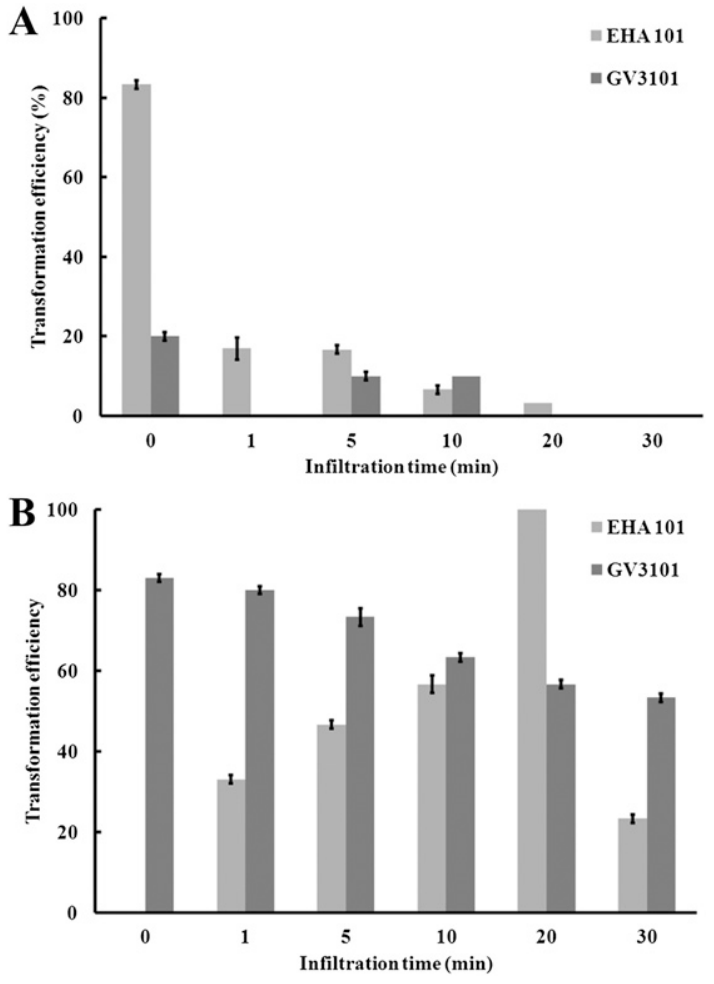

Fig. 8. The effect of vacuum infiltration on transformation efficiencies (mean \pm SE) of anthurium cultivars Local Pink (A) and KAIRI2010 (B). Means and SE were determined from three independent experiments, where $\mathrm{n}=30$. EHA101 (C58 chromosomal background with disarmed pTiBo542) and GV3101 (C58 chromosomal background with disarmed pTiC58) are Agrobacterium strains.

efficiencies varying between $0 \%$ and $82 \%$ among genotypes, before optimization of the protocol. Nevertheless, we show that after optimization, $100 \%$ transient transformation efficiency can be achieved in genotypes at both ends of the spectrum.

Although the spathe is a modified leaf, the leaf tissue, in general, was more amenable to Agrobacterium transient transformation. The spathe of anthurium contains anthocyanins in contrast to the leaves, which contain chlorophyll. Previous reports have demonstrated that pelargonidins have an inhibitory effect on the growth of Escherichia coli and Staphylococcus aureus (Hamdy et al., 1961). It is possible that the anthocyanins and possibly flavonoids may exert a negative influence on transient transformation. The fact that the white spathe of 'KAIRI2010', which lacks anthocyanins, was more readily transformed than the 'Local Pink' may lend some support to this idea.

Among the tissues examined in this article, the spathe and leaves yielded the best results with no transient transformation being observed with spadix tissue. Variation was also observed in the transient transformation efficiency with leaf age. Similar observations were noted in Artemisia (Mannan et al., 2009). In contrast, there were no significant differences in transformation efficiencies across plants of different maturity levels or tissues of different development stages in A. thaliana, tobacco, pepper (Capsicum annuum), cotton (Gossypium hirsutum), tomato, and lettuce (Joh et al., 2005; Wroblewski et al., 2005). This underlines the importance of investigation the effect of tissue developmental stage on transient transformation efficiency in each species.

It is well established in the literature that selection of the right infiltration medium (Du et al., 2010; Frame et al., 2002; 
McIntosh et al., 2004; Tague and Mantis, 2006), acetosyringone level (Kapila et al., 1997), and use of surfactants (Joh et al., 2005) can improve transformation efficiency. Optimizing the infiltration medium improved transient transformation efficiency in the difficult-to-transform 'KAIRI2010' from $\approx 14 \%$ to $62 \%$. In this study the best infiltration medium varied with cultivars, indicating that identifying a suitable infiltration medium may be among the most critical factors in improving transient transformation efficiency in anthurium similar to results obtained in other species (Cheng et al., 1997; Dong et al., 1996; EnriquezObregon et al., 1998; Fry et al., 1987; Lucca et al., 2001; Mohanty et al., 1999).

Acetosyringone, known to induce the virulence genes of Agrobacterium necessary for effecting the transfer and incorporation of T-DNA in the host plant (McCullen and Binns, 2006; Stachel et al., 1986), significantly improved the transient transformation efficiency up to a concentration of $100 \mu \mathrm{M}$, indicating the critical role of acetosyringone in anthurium transformation. Higher concentrations of acetosyringone, however, resulted in a decrease in transient transformation efficiency and, in some cases, completely inhibited it altogether. The inhibition at higher concentrations has been attributed to acetosyringone being toxic at high concentration (Sreeramanan et al., 2007).

Previous research has shown that the concentration of a surfactant can play a significant role in the success of transient assays (Chen et al., 2010; Li et al., 2009). Of the three surfactants used in this study, only S240 was able to increase the transient transformation efficiency. The other two surfactants resulted in a brown ring along the edge of leaf disc suggesting tissue death. Higher concentrations of S240, however, resulted in increasing levels of necrotic damage and a consequent decrease in transient transformation efficiency.

Different Agrobacterium strains have been reported to result in different transformation efficiencies (Akramian et al., 2008; Bauer et al., 2002; Dang and Wei, 2007; De Bondt et al., 1994; Yong et al., 2006) as was observed in our study. EHA101, GV3101, and LBA4404 are nononcogenic (disarmed) and have been used for transformation of a large variety of plants. In anthurium, all three strains have been used successfully in generating transgenic plants (Chen et al., 1997; Fitch et al., 2011; Zhao et al., 2010). In this study, EHA101 (a supervirulent strain with a derivative of the agropine/1,1-succinamopine-type Tiplasmid pTiBo542) (Hood et al., 1987) and GV3101, a derivative of a nopaline type Ti-plasmid (Koncz and Shell, 1986), were more effective in transient transformation of anthurium than LBA4404 that contains a octopine type Ti plasmid. There was some evidence that EHA 101 was somewhat more effective than GV3101, particularly with 'Local Pink'. In A. thaliana and maize (Zea mays), GV3101 resulted in the highest transformation frequencies, whereas EHA 101 and LBA4404 had medium and low transformation frequencies, respectively (Oltmanns et al., 2010) suggesting the importance of screening a number of Agrobacterium strains during optimization of transient assays.

Regardless of Agrobacterium strains used, the optimal growth phase (that gave the highest transient transformation efficiency) corresponded to $\mathrm{OD}_{600}$ of 1.5 , which corresponds to the middle exponential (logarithmic) growth phase for the strain used, consistent with the results obtained by Gao et al. (2009). However, previous studies of anthurium transformation have used an $\mathrm{OD}_{600}$ of 0.8 (Fitch et al., 2011; Zhao et al., 2010) suggesting that further optimization of stable transformation procedures should be performed with respect to the optimal growth phase.
From the results obtained, Agrobacterium concentration has a significant effect over a broad range of $\mathrm{OD}_{600}$ values from 0.1 to 1.5 , consistent with those from several other studies (Fitch et al., 2011; Kim et al., 2009; Santos-Rosa et al., 2008). The number of Agrobacterium cells in the inoculum is considered to be a critical factor in the efficiency of transformation. An excessive number of bacteria can stress plant cells and affect their regeneration potential, whereas low concentration can reduce the frequency of T-DNA transfer. Regardless of cultivar and growth phase, the optimum cocultivation time was $2 \mathrm{~d}$ with both cultivars KAIRI2010 and Local Pink. These observations were consistent with those previously recorded (Hayden and Christopher, 2004; Kuehnle et al., 2001).

In our study, the transient transformation efficiency improved with infiltration time in the inoculum up to the 16-h time point, after which there was a drastic decrease in transient transformation efficiency. This decrease can be attributed to the Agrobacterium overtaking the leaf discs, thereby increasing the incidence of cell death of the leaf discs. In previous studies investigating stable transformation of anthurium, the explants were immersed anywhere from a couple of minutes (Chen and Kuehnle, 1996; Chen et al., 1997) to 30 mins (Fitch et al., 2011; Zhao et al., 2010) again suggesting that further optimization of stable transformation protocols may lead to greater transformation efficiency.

Vacuum infiltration of Agrobacterium has been successfully used for the stable transformation of recalcitrant plants such as wheat, monterey pine (Pinus radiata), banana (Musa acuminata), lentil, and radish (Raphanus sativus) (Acereto-Escoffie et al., 2005; Adesoye et al., 2010; Amoah et al., 2001; Charity et al., 2002; Curtis and Nam, 2001; Mahmaudian et al., 2002). Vacuum infiltration, in our study, not only increased the proportion of discs transformed, but also the area of the disc that is transformed in 'KAIRI2010'. However, cultivar Local Pink did not benefit from this process often resulting in tissue death, indicating that in anthurium, response to vacuum infiltration may be genotypedependent.

The data presented here demonstrate that anthurium leaves can be used as a suitable system for carrying out transient expression studies and that optimal conditions for transient assays vary with cultivar and Agrobacterium strain used. We have shown in this study that using Agrobacterium strain GV3101 grown to an $\mathrm{OD}_{600}$ of 1.5 and resuspended to a final $\mathrm{OD}_{600}$ of 0.8 in infiltration medium 4 supplemented with $100 \mu \mathrm{M}$ acetosyringone and $0.05 \% \mathrm{~S} 240$, for an infiltration period of $16 \mathrm{~h}$ and a cocultivation time of $2 \mathrm{~d}$, yielded optimal results for cultivar Local Pink. Similar conditions were used for the transient transformation of 'KAIRI2010' using infiltration medium 2 and vacuum infiltration. Optimizing transient gene expression in tissues that can be regenerated into transgenic plants may have the added benefit of leading to the development of improved methodologies for stable transformation in A. andraeanum.

\section{Literature Cited}

Acereto-Escoffie, P.O.M., B.H. Chi-Manzanero, S. Echeverria-Echeverria, R. Grijalva, R.K.A. James, T. Gonzalez-Estrada, E. Castano, and L.C. Rodriguez-Zapata. 2005. Agrobacterium-mediated transformation of Musa acuminata cv. Grand Nain scalps by vacuum infiltration. Sci. Hort. 105:359-371.

Adesoye, A.I., A.O. Togun, and J. Machuka. 2010. Transformation of cowpea (Vigna unguiculata L. Walp.) by Agrobacterium infiltration. J. Appl. Biosci. 30:1845-1860. 
Akramian, M., S.M.F. Tabatabaei, and M. Mirmasoumi. 2008. Virulence of different strains of Agrobacterium rhizogenes on genetic transformation of four Hyoscyamus species. Amer. Eurasian J. Agr. Environ. Sci. 3:759-763.

Amoah, B.K., H. Wu, C. Sparks, and H.D. Jones. 2001. Factors influencing Agrobacterium-mediated transient expression of uidA in wheat inflorescence tissue. J. Expt. Bot. 52:1135-1142.

Bauer, N., D.L. Levanic, S. Mihaljevic, and S. Jelaska. 2002. Genetic transformation of Coleus blumei Benth. using Agrobacterium. Food Technol. Biotechnol. 40:163-169.

Baulcombe, D.C. 1999. RNA makes no protein. Curr. Biol. 9:599-601. Bhaskar, P.B., M. Venkateshwaran, L. Wu, J.-M. Ané, and J. Jiang. 2009. Agrobacterium-mediated transient gene expression and silencing: A rapid tool for functional gene assay in potato. PLoS ONE 4:e5812.

Charity, J.A., L. Holland, S.S. Donaldson, L. Grace, and C. Walter. 2002. Agrobacterium-mediated transformation of Pinus radiata organogenic tissue using vacuum infiltration. Plant Cell Tissue Organ Cult. 70:51-60.

Chen, F.-C. and A.R. Kuehnle. 1996. Obtaining transgenic Anthurium through Agrobacterium-mediated transformation of etiolated internodes. J. Amer. Soc. Hort. Sci. 121:47-51.

Chen, F.-C., A.R. Kuehnle, and N. Sugii. 1997. Anthurium roots for micropropagation and Agrobacterium tumefaciens-mediated gene transfer. Plant Cell Tissue Org. Cult. 49:71-74.

Chen, X., R. Equi, H. Baxter, K. Berk, J. Han, S. Agarwal, and J. Zale. 2010. A high-throughput transient gene expression system for switchgrass (Panicum virgatum L.) seedlings. Biotechnol. Biofuels 3:9.

Cheng, M., J.E. Fry, S. Pang, I. Zhou, C. Hironaka, D.R.I. Duncan, T.W.L. Conner, and Y. Wang. 1997. Genetic transformation of wheat mediated by Agrobacterium tumefaciens. Plant Physiol. 115:971-980.

Christou, P. 1997. Rice transformation. Bombardment. Plant Mol. Biol. 35:197-203.

Collette, V.E. 2002. A molecular analysis of flower color development in an ornamental monocot (Anthurium andraeanum). PhD diss., Massey Univ., Palmerston North, New Zealand.

Collette, V.E., P.E. Jameson, K.E. Schwinn, P. Umaharan, and K.M. Davies. 2004. Temporal and spatial expression of flavonoid biosynthetic genes in flowers of Anthurium andraeanum. Physiol. Plant. 122:297-304.

Curtis, I.S. and H.G. Nam. 2001. Transgenic radish (Raphanus sativus L. longipinnatus Bailey) by floral dip method plant development and surfactant are important in optimizing transformation efficiency. Mol. Breed. 8:37-52.

Dang, W. and Z. Wei. 2007. An optimized Agrobacterium-mediated transformation for soybean for expression of binary insect resistance genes. Plant Sci. 173:381-389.

De Bondt, A., K. Eggermont, P. Druart, M.D. Vil, L. Goderis, J. Vanderleyden, and W.F. Broekaert. 1994. Agrobacterium-mediated transformation of apple (Malus domestica Borkh.): An assessment of factors affecting gene transfer efficiency during early transformation steps. Plant Cell Rpt. 13:587-593.

Dong, J., W. Teng, W.G.L. Buchhol, and T.C. Hall. 1996. Agrobacteriummediated transformation of javanica rice. Mol. Breed. 2:267-276.

Du, H., H. Wu, J. Yang, and J. Li. 2010. Effects of basal media, salt concentrations, antioxidant supplements and co-effects on the Agrobacterium-mediated transformation efficiency in maize. Afr. J. Biotechnol. 9:1135-1143.

Dufour, L. and V. Guérin. 2003. Growth, developmental features and flower production of Anthurium andraeanum Lind. in tropical conditions. Sci. Hort. 98:25-35.

Enriquez-Obregon, G.A., R.I. Vazquez-Padron, D.L. Prieto-Samsonov, G.A. de la Riva, and G. Selman-Housein. 1998. Herbicide-resistant sugarcane (Saccharum officinarum L.) plants by Agrobacteriummediated transformation. Planta 205:20-27.

Fischer, R. and N. Emans. 2000. Molecular farming of pharmaceutical proteins. Transgenic Res. 9:279-299.
Fitch, M.M.M., T.C.W. Leong, H.R.K. McCafferty, Y.J. Zhu, P.H. Moore, D. Gonsalves, H.S. Aldwincle, and H.J. Atkinson. 2011. Improved transformation of Anthurium. HortScience 46:358-364.

Frame, B.R., H. Shou, R.K. Chikwaba, Z. Zhang, C. Xiang, T.M. Fonger, S.K. Pegg, B. Li, D.S. Nettleton, D. Pei, and K. Kan Wang. 2002. Agrobacterium tumefaciens-mediated transformation of maize embryos using a standard binary vector system. Plant Physiol. 129:13-22.

Frederick, R.D., R.L. Thilmony, G. Sessa, and G.B. Martin. 1998. Recognition specificity for the bacterial avirulence protein AvrPto is determined by Thr-204 in the activation loop of the tomato Pto kinase. Mol. Cell 2:241-245.

Fry, J., A. Barnason, and R.B. Horsch. 1987. Transformation of Brassica napus with Agrobacterium tumefaciens based vectors. Plant Cell Rpt. 6:321-325.

Gao, N., W. Shen, Y. Cao, Y. Su, and W. Shi. 2009. Influence of bacterial density during preculture on Agrobacterium-mediated transformation of tomato. Plant Cell Tissue Organ Cult. 98:321-330.

Hamdy, M.K., D.E. Pratt, J.J. Powers, and D. Somaatmadja. 1961. Anthocyanins. III. Disc sensitivity assay of inhibition of bacterial growth by pelargonidin 3-monoglucoside and its degradation products. J. Food Sci. 26:457-461.

Hassan, F., M.I. Hoque, H. Kiesecker, and H. Jacobsen. 2007. Transient GUS expression in decapitated lentil embryos. Plant Tissue Cult. Biotechnol. 17:97-102.

Hayden, D.M. and D.A. Christopher. 2004. Characterization of senescence-associated gene expression and senescence-dependent and -independent cysteine proteases differing in microsomal processing in Anthurium. Plant Sci. 166:779-790.

He, Y., H.D. Jones, S. Chen, X.M. Chen, D.W. Wang, K.X. Li, D.S. Wang, and L.Q. Xia. 2010. Agrobacterium-mediated transformation of durum wheat (Triticum turgidum L. var. durum cv. Stewart) with improved efficiency. J. Expt. Bot. 61:1567-1581.

Hood, E.E., R.T. Fraley, and M.D. Chilton. 1987. Virulence of Agrobacterium tumefaciens strain A281 on legumes. Plant Physiol. 83:529-534.

Joh, L.D., T. Wroblewski, N.N. Ewing, and J.S. VanderGheynst. 2005. High-level transient expression of recombinant protein in lettuce. Biotechnol. Bioeng. 91:861-871.

Kapila, J., R. DeRycke, M. Van Montagu, and G. Angenon. 1997. An Agrobacterium-mediated transient gene expression system for intact leaves. Plant Sci. 122:101-108.

Kim, M.J., K. Baek, and C.M. Park. 2009. Optimization of conditions for transient Agrobacterium-mediated gene expression assays in Arabidopsis. Plant Cell Rpt. 28:1159-1167.

Koncz, C. and J. Shell. 1986. The promoter of TL-DNA gene 5 controls tissue-specific expression of chimeric genes carried by a novel type of Agrobacterium binary vector. Mol. Gen. Genet. 204:383-396.

Kuehnle, A. and F.-C. Chen. 1994. Genetic transformation in Anthurium. Biotechnol. Agr. For. 29:217-225.

Kuehnle, A.R., F.-C. Chen, and N. Sugii. 2001. Transgenic Anthurium, p. 3-15. In: Bajaj, Y.P.S. (ed.). Biotechnology in agriculture and forestry. Vol. 48. Transgenic crops III. Springer-Verlag, Berlin, Germany.

Kuehnle, A.R., T. Fujii, F.-C. Chen, A. Alvarez, N. Sugii, R. Fukui, S.L. Aragon, and J.M. Jaynes. 2004. Peptide biocides for engineering bacterial blight tolerance and susceptibility in cut-flower Anthurium. HortScience 39:1327-1331.

Li, J., E. Park, A.G. von Armin, and A. Nebenführ. 2009. The FAST technique: A simplified Agrobacterium-based transformation method for transient gene expression analysis in seedlings of Arabidopsis and other plant species. Plant Methods 5:6.

Lucca, P., X. Ye, and I. Potrykus. 2001. Effective selection and regeneration of transgenic rice plants with mannose as selective agent. Mol. Breed. 7:43-49.

Mahmaudian, M., M. Yucel, and H.A. Oktem. 2002. Transformation of lentil (Lens culinaris M.) cotyledonary nodes by vacuum infiltration of Agrobacterium tumefaciens. Plant Mol. Biol. Rpt. 20:251-257. 
Manavella, P.A. and R.L. Chan. 2009. Transient transformation of sunflower leaf discs via an Agrobacterium-mediated method: Applications for gene expression and silencing studies. Nat. Protoc. 4:1699-1707.

Mannan, A., T.N. Syed, and B. Mirza. 2009. Factors affecting Agrobacterium tumefaciens mediated transformation of Artemisia absinthium L. Oak. J. Bot. 41:3239-3246.

McCullen, C.A. and A.N. Binns. 2006. Agrobacterium tumefaciens and plant cell interactions and activities required for interkingdom macromolecular transfer. Annu. Rev. Cell Dev. Biol. 22:101-127.

McIntosh, K.B., J.L. Hulm, L.W. Young, and P.C. Bonham-Smith. 2004. A rapid Agrobacterium-mediated Arabidopsis thaliana transient assay system. Plant Mol. Biol. Rpt. 22:53-61.

Mestre, P., G. Brigneti, and D.C. Baulcombe. 2000. An Ry-mediated resistance response in potato requires the intact active site of the NIa proteinase from potato virus Y. Plant J. 23:653-661.

Mohanty, A., N.P. Sarma, and A.K. Tyagi. 1999. Agrobacteriummediated high frequency transformation of an elite indica rice variety Pusa Basmati 1 and transmission of the transgene to R2 progeny. Plant Sci. 147:127-137.

Negrouk, V., G. Eisner, H. Lee, K. Han, D. Taylor, and H.C. Wong. 2005. Highly efficient transient expression of functional recombinant antibodies in lettuce. Plant Sci. 169:433-438.

Oltmanns, H., B. Frame, L. Lee, S. Johnson, B. Li, K. Wang, and S.B. Gelvin. 2010. Generation of backbone-free, low transgene copy plants by launching T-DNA from the Agrobacterium chromosome. Plant Physiol. 152:1158-1166.

Santos-Rosa, M., A. Poutaraud, D. Merdinoglu, and P. Mestre. 2008. Development of a transient expression system in grapevine via agroinfiltration. Plant Cell Rpt. 27:1053-1063.

Scofield, S.R., C.M. Tobias, J.P. Rathjen, J.H. Chang, D.T. Lavelle, R.W. Michelmore, and B.J. Staskawicz. 1996. Molecular basis of gene-for-gene specificity in bacterial speck disease of tomato. Science 274:2063-2065.

Sreeramanan, S., M. Maziah, M.P. Abdullah, M. Sariah, and M.N. Aini. 2007. Physical and biological parameters affecting transient
GUS and GFP expressions in banana via particle bombardment. Asia Pac. J. Mol. Biol. Biotechnol. 13:35-57.

Stachel, S.E., E.W. Nester, and P.C. Zambryski. 1986. A plant cell factor induces Agrobacterium tumefaciens vir gene expression. Proc. Natl. Acad. Sci. USA 83:379-383.

Tague, B.W. and J. Mantis. 2006. In planta Agrobacterium-mediated transformation by vacuum infiltration. Methods Mol. Biol. 232:215-223.

Tsuda, K., Y. Qi, L.V. Nyugen, G. Bethke, Y. Tsuda, J. Glazebrook, and F. Katagiri. 2011. An efficient Agrobacterium-mediated transient transformation of Arabidopsis. Plant J. 69:713-719.

van der Hoorn, R.A.L., F. Laurent, R. Roth, and P.J.G.M. De Wit. 2000. Agroinfiltration is a versatile tool that facilitates comparative analyses of Avr9/cf-9-induced and Avr4/Cf-4-induced necrosis. Mol. Plant Microbe Interact. 13:439-446.

Vaquero, C., M. Sack, J. Chandler, J. Drossard, F. Schuster, M. Monecke, S. Schillberg, and R. Fischer. 1999. Transient expression of a tumor specific single-chain fragment and a chimeric antibody in tobacco leaves. Proc. Natl. Acad. Sci. USA 96:11128-11133.

Wroblewski, T., A. Tomczak, and R. Michelmore. 2005. Optimization of Agrobacterium-mediated transient assays of gene expression in lettuce, tomato and Arabidopsis. Plant Biotechnol. J. 3:259-273.

Yasmin, A. and T. Debener. 2010. Transient gene expression in rose petals via Agrobacterium infiltration. Plant Cell Tissue Organ Cult. 102:245-250.

Yong, W.T.L., J.O. Abdullah, and M. Mahmood. 2006. Optimization of Agrobacterium-mediated transformation parameters for Melastomataceae spp. using green fluorescent protein (GFP) as a reporter. Sci. Hort. 109:78-85.

Zhao, Q., J. Jing, G. Wang, J.H. Wang, Y.Y. Feng, H.W. Xing, and C.F. Guan. 2010. Optimization in Agrobacterium-mediated transformation of Anthurium andraeanum using GFP as a reporter. Electron. J. Biotechnol. 13:doi: 10.2225/vol13-issue5-fulltext-2.

Zottini, M., E. Barizza, A. Costa, E. Formentin, C. Ruberti, F. Carimi, and F. Lo Schiavo. 2008. Agroinfiltration of grapevine leaves for fast transient assays of gene expression and for long-term production of stable transformed cells. Plant Cell Rpt. 27:845-853. 